Research Article

\title{
Seismic Performance Assessment of a Multistorey Building Designed with an Alternative Capacity Design Approach
}

\author{
Marco Bovo $\mathbb{D}^{1},{ }^{1}$ Marco Savoia $\mathbb{D}^{2},{ }^{2}$ and Lucia Praticò $\mathbb{D}^{2}$ \\ ${ }^{1}$ DISTAL, Alma Mater Studiorum Università di Bologna, Viale Fanin 48, 40127 Bologna, Italy \\ ${ }^{2}$ DICAM, Alma Mater Studiorum Università di Bologna, Viale Risorgimento 2, 40136 Bologna, Italy \\ Correspondence should be addressed to Marco Bovo; marco.bovo@unibo.it
}

Received 5 December 2019; Revised 25 March 2021; Accepted 10 May 2021; Published 24 May 2021

Academic Editor: Hui Yao

Copyright (c) 2021 Marco Bovo et al. This is an open access article distributed under the Creative Commons Attribution License, which permits unrestricted use, distribution, and reproduction in any medium, provided the original work is properly cited.

The actual seismic building codes have a prescriptive nature, and they are principally aimed to guarantee a prescribed life-safety level against a design-level earthquake even if some methods have been proposed to evaluate the seismic performance of a building along its entire service life. Among these, the performance-based seismic design method permits the design of buildings with a more realistic understanding of both risk of life for occupants and economic losses that may occur in future earthquakes. On the other side, the capacity design method, providing criteria to properly spread the inelastic deformation demand between the different structural elements, allows to establish a ductile collapse mechanism avoiding undesired brittle failures. In this context, modern building codes consider the adoption of a single value for the behaviour factor $q$ to be used in the design process. All this should be argued since, especially for buildings characterized by storeys with different uses and occupancy ratios, the adoption of a single value for $q$ could guide the design process to a solution not minimizing the seismic loss. With reference to these aspects, the paper shows the comparison of the seismic responses of a multistorey framed building designed following two different approaches. The first approach, suggested by many international codes, follows the capacity design rules and considers a single value for the behaviour factor valid for the whole building. In this first case, the damage mechanisms could affect, theoretically, every storey of the building. The second approach, proposed here, considers instead the possibility to adopt different behaviour factors to attribute to different storeys. In this way, it is possible to concentrate and localize the most severe earthquake-induced structural damage on (few) storeys, selected by the designers. By means of the seismic performance assessment methodology, the comparison between the two building responses is provided in terms of expected losses during the whole building service life and is reported in terms of both economical loss and human life loss. The results in the paper show that, if different behaviour factors are properly selected for different storeys, the design process can provide a solution characterized by lower values of seismic loss with respect to the case of the design assuming a single- $q$ value.

\section{Introduction}

The up-to-date seismic design philosophy worldwide accepted establishes that a structure, to overcome an earthquake without to collapse, can face the seismic event by reaching high deformation level (typically in the inelastic field) and exhibiting ductile damage mechanisms, like the plastic hinges formation. Thus, part of the incoming earthquake energy is dissipated in hysteretic energy that can be also associated to severe damage of both structural and nonstructural elements [1]. The current capacity design method, developed in an academic context for the seismic design of buildings and included nowadays in many international codes [2-6], furnishes criteria for calculating structural elements and constructive details for the design of the new seismic-resistant building generation. The current building codes have a prescriptive nature and have the main aim to establish a design process providing buildings with a certain failure probability at a specific ultimate limit state for a particular design-level event or intensity. While building codes allow obtaining structures that meet a life-safety performance level for a specified seismic intensity level, they usually do not request for the respect of other performance levels. Moreover, codes do not furnish criteria to define if 
other performance levels (e.g., those connected to serviceability limit states) would be guaranteed by the designed structure [7]. However, the expected structural performance and thus the actual amount of damage and losses occurring for a generic seismic intensity are typically not calculated [8]. Even recently, earthquakes continue to highlight the thorny dilemma of the destiny of structures that withstand the seismic action, reporting extensive structural and nonstructural damage resulting out of service for a long period and requesting high disbursement for their restoration [9]. Therefore, recently, an increasing attention has been placed on the definition of criteria for the design of more resilient structures. So, the new design criteria have started to include the minimization of disruption and costs associated with the post-earthquake retrofitting, as well as safety and financial aspects [10-14].

In this field, the performance-based seismic design (PBSD), formulated in the Vision 2000 document [15] and then enriched by several researchers, e.g., Otani [16], Poland and Hom [17], Kawashima [18], Kappos [19], and Priestley [20], is a broader concept that permits the design of buildings with a realistic and reliable understanding of the life risk for occupants and the seismic induced economic loss that may occur during the service life of a structure [21]. In particular, PBSD, starting from the assessment of the seismic response of a building, allows to determine the probability of experiencing different loss consequences, considering a range of potential seismic scenarios that may hit the structure during its service life [22]. To date, an increasing interest has been addressed in the reduction of losses due to seismic damage of structures, either directly related to repair costs or indirectly associated with loss of nonstructural element functionality or even casualties.

The assessment of the expected loss could be an interesting tool for a reliable and objective comparison of the seismic performance of different buildings or for the comparison between different design solutions for the same building, as discussed in Mahin et al. [12]. The performancebased optimum seismic design should allow for a significant reduction of the direct construction cost combined with an improved control of the seismic performance under earthquake loading [23-25].

On the other side, after the development in the 1970's of the aforementioned capacity design method [26], even now considered to be the starting point of the performance-based seismic design, the attention of the researchers has been focused on the evaluation of the seismic demand on inelastic systems. Thus, the definition of practical tools to use for the reduction of seismic actions on structural elements has been developed in order to take into account the presence of inelastic deformations. Regarding this, several studies, e.g., [27-30] have focused on the calibration and definition of the behaviour factor, which is defined as $q$ in the Eurocode 8 [3]. This parameter aims at reducing the elastic spectrum into a design spectrum by dividing it using $q$, which is higher than one. The selection of the appropriate $q$ value is a crucial point of the seismic design phase since $q$ is strictly correlated to the capacity of the structure to dissipate energy, mainly through the ductile behaviour of its structural elements, clearly involving hysteretic damage. In the seismic design process, it is quite common to adopt a single $q$ value, which is used for the force-based design of different structural elements assuming implicitly that every element of the structure can be damaged by a design-level seismic event (distributed damage concept). Alternative approaches, for example, based on selective weakening criterion, have been proposed in [31-34] to drive the degradation mechanism of the structures towards concentrated damage seismic scenarios (concentrated damage concept). All this could provide, in the future, a valid alternative to the distributed seismic damage scenario expected in case of the adoption of the current codes compliant approaches, for the design of new structures. The basis of a selective weakening strategy is to modify the inelastic mechanism towards a more desirable mechanism by first weakening selected regions of the structure and avoiding brittle failure mechanisms. Subsequently, if necessary, the structure is further upgraded to the desired strength/stiffness/ ductility and energy dissipation capacity.

Similar to this approach, by following the general rules of the capacity-based method, in this paper, an alternative seismic design approach is numerically investigated. In fact, a selective strength weakening has been introduced in the design phase of a new building by selecting different behaviour factors for storeys with different uses or different occupancy ratios (number of people per unitary surface). The main aim of the introduction of different $q$ values in the seismic capacity design approach is to modify the inelastic damage mechanism of the structure, by considering reduced strength values for specific members within the structural system and guiding the building towards a mechanism that reduces the seismic loss.

Then, the paper illustrates the comparison between the different seismic responses of a 6-storey building designed following two different approaches. The first structure has been designed following the consolidated capacity design approach described in the Eurocode 8 [3], with a single $q$ value and producing a system inclined to spread damage on various storeys (distributed damage approach). The second structure, obtained following the alternative capacity design approach proposed in this paper, has been designed by considering different $q$ values along the height of the building, to concentrate the most of the seismic degradation in selected storeys (concentrated damage approach). Figure 1 depicts a schematic representation of the two different approaches considered in the design phase. The seismic performances of the two design proposals have been compared in terms of four different performance measures as follows:

(i) Number of fatalities occurred during or in the aftermath of the event

(ii) Number of injured people during the event

(iii) Repair cost for the replacement/refurbishment of the damaged elements

(iv) Repair time for the building restoration

These indicators have been calculated following the PBSD method described in the document FEMA P-58-1 
[21]. The methodology of the FEMA P-58-1 considered in this paper, also known as PEER framework [35], makes use of the probability theorem to predict the consequences (losses) of an earthquake in terms of the indicators introduced above, which are calculated as a multiple integer of the different levels of expected seismic intensity. However, being impossible to obtain the exact closed solution of such integrals, in order to evaluate the results of the integral analysis by a statistical approach, a numerical modified Monte Carlo method, as detailed in Yang et al. [36], has been considered.

\section{Description of the Two Capacity Design Approaches}

2.1. Single-q (1q) Design Approach. The first approach considered in the work is the consolidated (traditional) capacity-based approach detailed in the Eurocode 8 [3]. In this approach, the sizing of the elements is performed on the basis of a single behaviour factor $q$ that must be properly assumed by the designer. The code-compliant $q$ value assumed here takes into account for the overall nonlinear response of the structure depending on material, structural system, and design procedures.

2.2. Variable- $q(v q)$ Design Approach. The second design approach is an alternative method proposed by the authors in this study. It envisages the possibility to assume different $q$ values for the different storeys of a generic multistorey building. The flowchart with the main steps of this alternative approach is displayed in Figure 2. Starting from the traditional design approach, performed considering a single $q$ value and adopted for the sizing of the gross-section of reinforced concrete (RC) structural elements, the alternative approach considers differentiated $q$ values for the design of the steel reinforcement bars (rebars) of the structural elements of the generic storey. The alternative procedure has been set with the constraint to guarantee that structures designed with the alternative procedure have analogous failure probability (i.e., collapse probability) as structures designed with the traditional approach. This allows to set a reliable comparison between the seismic responses and the expected performances of the two different structures. So, after the structure design has been performed with the traditional approach, the building fragility curve $P\left(\mathrm{Sa}_{\mathrm{T} 1}\right)_{1 q}$ at the collapse prevention limit state has been obtained by means of the incremental dynamic analysis (IDA) procedure [37]. Fragility functions are a useful tool for assessing the seismic vulnerability of a structure at a certain damage state, depending on a properly selected intensity measure [38]. In the definition of the failure probability function $P(\cdot)$, the variable $\mathrm{Sa}_{\mathrm{T} 1}$ represents the spectral acceleration at the first natural period of vibration $T_{1}$. Then, after the selection of the $q$ value for each storey, the variable- $q$ design process has been performed to define the alternative rebar configuration. Then, the fragility curve of the second structure, for the same collapse prevention limit state, has been evaluated again with the IDA procedure. Finally, the central values (i.e., the median values of the spectral acceleration for the two different distributions) $\mathrm{Sa}_{\mathrm{T} 1,1 q}$ and $\mathrm{Sa}_{\mathrm{T} 1, v q}$ have been obtained and selected for comparison. If the value of $\mathrm{Sa}_{\mathrm{T} 1, v q}$ is in the range from $0.95 \mathrm{Sa}_{\mathrm{Tl}, 1 q}$ to $1.05 \mathrm{Sa}_{\mathrm{Tl}, 1 q}$ (selected by engineering judgement to be a suitable range of acceptance), the alternative design process is completed. If the differences between the values are not negligible (i.e., $\mathrm{Sa}_{\mathrm{Tl}, v q}$ value results out of the previous range), the alternative design process with variable- $q$ must restart with a different hypothesis on the $q$ value dataset. In this term, the design procedure is very general and the proper selection of the $q$ dataset is left to the designer, clearly in the respect of the minimum and maximum values prescribed by the building code adopted in the design process (Eurocode 8 in this paper). It is also to emphasize how, also in this alternative variable- $q$ approach, a weak storey mechanism is avoided because of the application of the capacity design rules that prescribe the formation of plastic hinges in the beams avoiding both plastic hinges in the columns and brittle failure (e.g., shear failure) of the elements.

The main aim of this alternative design approach is to evaluate whether a diversification of the $q$ value for the different storeys (or, i.e., of the ductility demand and as a consequence, of the expected damage at the storey) can lead to a reduction of the average annual expected loss for the building.

It is clear that the design procedure following this approach could be iterative. Therefore, it is suitable to be introduced in a routine that, through a minimization (or optimization) approach, could lead to the definition of the vector of $q$ values minimizing a cost function (e.g., a loss measure). Of course, this function cannot be valid in general because it could be linked to both the reduction of economic losses and reduction of consequences to occupants (e.g., number of casualties). This last aspect is beyond the scope of the paper and will be object of future investigations. In the following sections, the process described herein will be applied to a building selected as a case study to show the advantages, in terms of reducing both economic and human losses, related to the adoption of this alternative design approach.

\section{The Case Study Building}

For the study, a hospital building characterized by high concentration and presence of human life has been adopted. The 6-storey structure has RC moment-resisting bare frames (MRBFs) in both horizontal directions in plan. It has $36 \mathrm{~m} \times 25 \mathrm{~m}$ in plan dimensions (surface of $900 \mathrm{~m}^{2} /$ floor) and $4 \mathrm{~m}$ of interstorey height (the total height of the building is $24 \mathrm{~m}$ ). The spacings between the frames are $6.0 \mathrm{~m}$ and $5.0 \mathrm{~m}$ in $X$ and $Y$ directions, respectively. The six bays of the beams in $X$ direction are $6.0 \mathrm{~m}$ long, while the five bays of the beams in $Y$ direction are $5.0 \mathrm{~m}$ long. The gross-sections of the columns are $60 \mathrm{~cm} \times 60 \mathrm{~cm}$ for first and second storeys, $50 \mathrm{~cm} \times 50 \mathrm{~cm}$ for the third and fourth, and $40 \mathrm{~cm} \times 40 \mathrm{~cm}$ for the other storeys. The beam sections are $40 \mathrm{~cm} \times 60 \mathrm{~cm}$ for all storeys. The plan view of the typical storey and a threedimensional view of the structural frames are shown in Figures 3(a) and 3(b). The concrete for structural elements 
has been assumed C28/35 class and for the steel rebars has been considered a B450C class. The mechanical properties of the materials have been calculated according to Eurocode 8 . The structure has been designed by considering, for the intermediate floors, a distributed dead load from structural elements $G_{1, k}=3.3 \mathrm{kN} / \mathrm{m}^{2}$, a distributed dead load from nonstructural elements $G_{2, k}=3.5 \mathrm{kN} / \mathrm{m}^{2}$, and a distributed live load $Q_{k}=3.0 \mathrm{kN} / \mathrm{m}^{2}$. For the roof, a distributed dead load from structural elements $G_{1, k}=3.0 \mathrm{kN} / \mathrm{m}^{2}$, a distributed dead load from nonstructural elements $G_{2, k}=1.2 \mathrm{kN} / \mathrm{m}^{2}$, and a distributed live load $Q_{k}=1.2 \mathrm{kN} / \mathrm{m}^{2}$ have been considered.

Assuming an occupancy ratio of 8 people $/ 100 \mathrm{~m}^{2}$ for each storey [39], the maximum occupancy capacity of the structure, i.e., the maximum number of people that can be contemporary present in the building, is equal to 432 people. It has been assumed that the building is located in Oakland (California, USA).

The structure of the building has been seismically designed in accordance with prescriptions of Eurocode 8 [3] - following both different design approaches described before-by means of dynamic response spectra analysis considering an elastic response spectrum at the collapse prevention limit state with peak ground acceleration (PGA) equal to $0.7 \mathrm{~g}$. Therefore, the design-level event has a probability of exceedance equal to $5 \%$ in 50 years corresponding to a return time of 975 years. The elastic finite element (FE) model of the building has been realized with the software OpenSEES [40].

For the first seismic design approach (i.e., single-q), a behaviour factor $q$ equal to 3.0 has been adopted for all storeys. In the second approach (i.e., variable-q), the behaviour factors for the two lowest storeys have been assumed equal to 4.5, whereas for the mid-high storeys, it has been assumed equal to the unitary value (i.e., adoption of the elastic spectrum). The behaviour factor distributions adopted in the work are depicted in Figure 3. The $q$-factors have been taken in accordance with the Eurocode 8 [3] for dissipative RC structures. The main aim of the alternative design approach is to obtain a rebar distribution concentrating the dissipation and consequently the damage in the desired storeys, in this case the two storeys at the base of the building. With reference to the alternative approach, the adoption of the behaviour factor values showed in Figure 3 provides some benefits with respect to the adoption of a unitary $q$ value for all storeys. In fact, the adoption of a behaviour factor higher than the unitary value reduces the high peak floor acceleration values expected at the higher storeys of a multistorey framed building [41]. Further details about the values of the peak floor acceleration obtained for the structures will be provided in the following.

The gross-section of the structural elements has been considered the same for the two cases. The analysis of the structure designed following the second approach has provided a (central) spectral acceleration value very close to that obtained in the first approach. Moreover, the quantities of rebars to adopt in the two approaches, for the elements of the whole building, are rather similar. Then, it is possible to assume that the construction costs of the two buildings, designed with the two different approaches, are practically the same. As an example, the rebars of column sections and beam sections affected by the maximum bending moment are reported in Table 1 for both approaches described before. As far as the degradation mechanism is concerned, with the values of $q$ adopted in the two different approaches, it is expected that the single- $q$ structure exhibits a distributed damage mechanism whereas the variable- $q$ structure is characterized by a concentrated damage mechanism involving a few storeys only.

\section{Seismic Response Evaluation}

4.1. Nonlinear FE Modelling. Starting from the linear elastic FE model used for the design phase, two inelastic FE models, associated with the structures designed following the two different approaches, have been realized. The detailed inelastic models have been adopted in the nonlinear time history analyses and carried out to evaluate the seismic response of the two structures. Numerical modelling and the following nonlinear seismic analyses have been performed with the software OpenSEES [40]. As an example, Figure 4 reports a lateral view of a perimeter frame (in $Y$ direction) of the building with location and numeration of the nodes of the model. The numerical models of the structures use elastic $1 \mathrm{D}$ finite elements for beams and columns. At their extremities, lumped flexural plastic hinges modelled by means of zero-length elements (equivalent to the behaviour of one-component lumped plasticity elements) have been introduced. The trilinear moment-rotation plastic hinges were modelled with hysteretic material [40]. At the ground level, the columns have been fully clamped at their base. The masses corresponding to structural dead loads, nonstructural dead loads, and live loads have been considered as equivalent distributed masses on the beams. The mean material properties adopted in the models, considered for the definition of the moment-rotation plastic hinges, have been assumed in accordance with the Eurocode 8 [3]. The main points of the backbone curves of the plastic hinges were calculated as recommended in NTC [5] and CEN [3], considering the axial load provided by vertical actions. The rigid floor assumption has been introduced in the model with the application of storey rigid links, preventing the horizontal relative displacements between nodes of the same floor.

It is worth saying that the two FE models differ only in the values of the characteristics of the plastic hinges, since different reinforcements have been designed (see Section 2). The structures investigated have first vibrating period equal to $T_{1 X}=0.78 \mathrm{~s}$ and $T_{1 Y}=1.13 \mathrm{~s}$, respectively, in $X$ and $Y$ directions. The structural parameters monitored at every storey during the time history analyses are the peak floor acceleration, the peak of interstorey drift, and the storey residual drift.

4.2. Definition of the Seismic Input. The comparison between the structural performances of the two structures adopting two different design approaches has been based on the structural parameter outcomes of a series of time history 


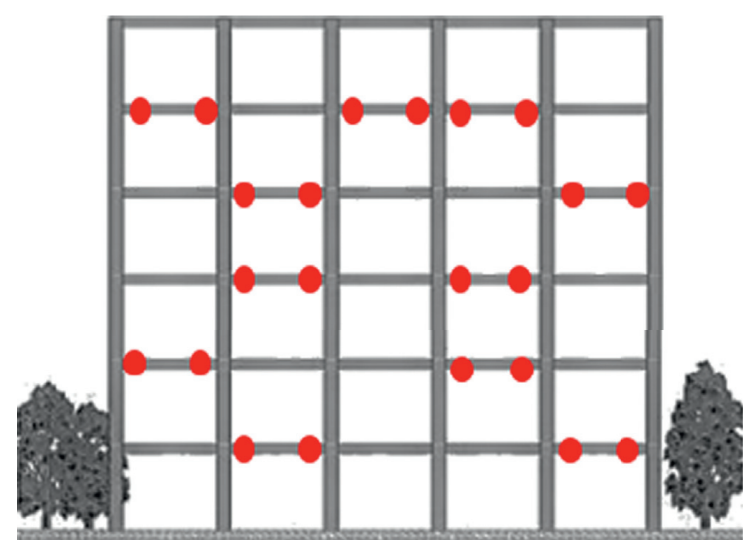

(a)

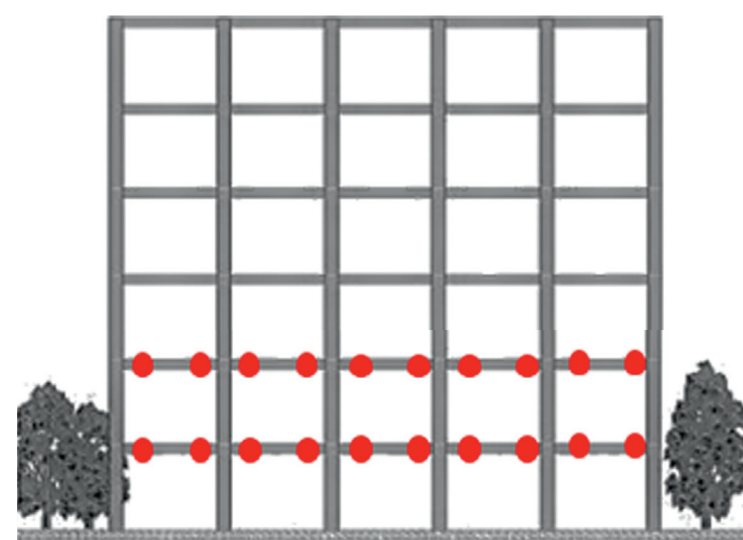

(b)

FIGURE 1: Illustration of the different possible damage distributions resulting from the two different approaches considered in this paper: (a) distributed damage mechanism with plastic hinges along the building elevation and affecting several storeys; (b) concentrated damage mechanism with plastic hinges located in the selected building storeys.

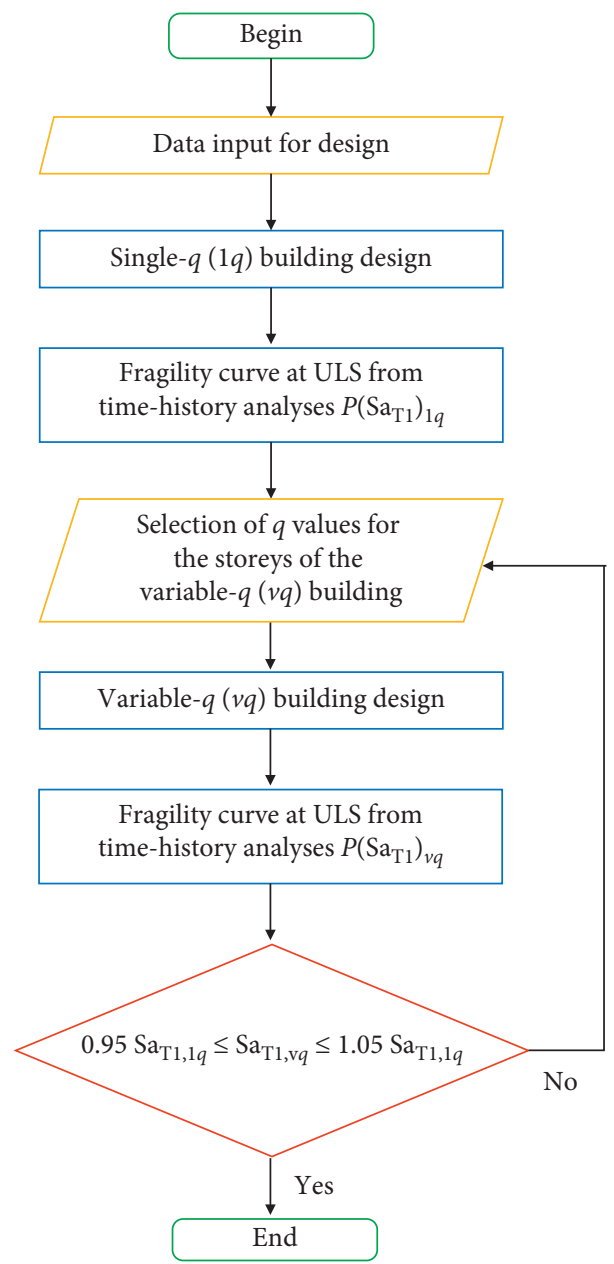

FIgURE 2: Flow chart of the alternative capacity design approach proposed in this paper.

analyses on the FE models. The structural parameters previously cited (i.e., peak floor acceleration, peak of interstorey, drift and storey residual drift) represent the input data for the subsequent loss assessment procedure. To capture the whole three-dimensional response of the building subjected to an earthquake, in this work, the seismic 


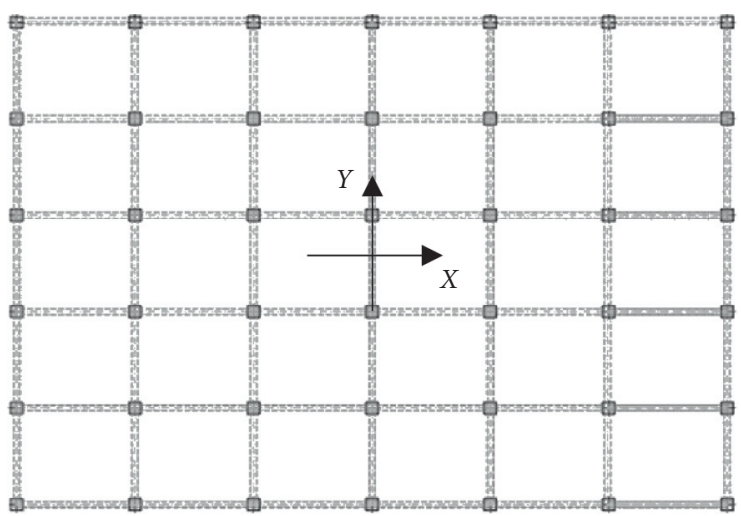

(a)

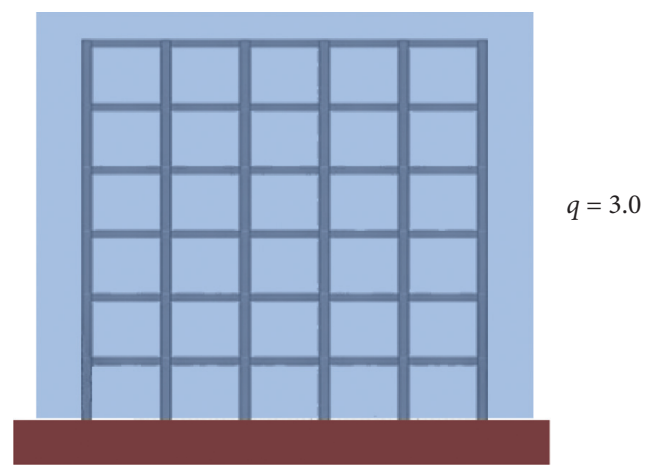

(c)

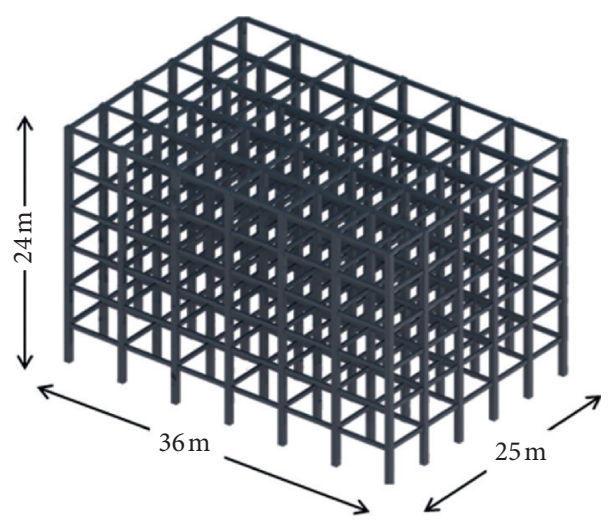

(b)

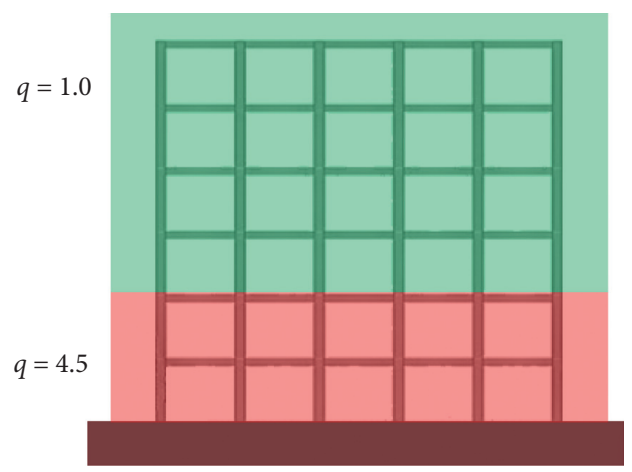

(d)

Figure 3: The 6-storey building selected as case study: (a) plan view of the typical storey and (b) three-dimensional view of the structural frames. Lateral view of the building with indication of the behaviour factor values adopted in the two design approaches: (c) single- $q$ case and (d) variable- $q$ case.

input has been introduced by two acceleration time history records acting along the two main horizontal directions of the models, i.e., $X$ and $Y$ (see the axes in Figure 3 ).

A set of 30 pairs of recorded acceleration time histories were selected and extracted from Pacific Earthquake Engineering Research (PEER) Center strong motion database [42] to cover a wide range of frequency content, time duration, and amplitude, with reference to the horizontal seismic components. They represent a seismological scenario with moment magnitude $\mathrm{Mw}$ ranging from 6.5 to 8.0, recorded at a distance $R$ of $6-50 \mathrm{~km}$ from the fault rupture. The set adopted here is the same used in Zucconi et al. [43]. The horizontal peak ground acceleration PGA ranges from $0.07 \mathrm{~g}$ to $0.48 \mathrm{~g}$. They have been recorded on $\mathrm{B}$ or $\mathrm{C}$ soil class (according to Eurocode 8 definition). The set of records adopted in the analyses have been selected in accordance with the work of Baker et al. [44].

In order to perform a time-based loss assessment analyses (see [21]), different seismic scenarios must be investigated. In this work, ten different seismic scenarios, corresponding to ten different seismic intensity levels, have been considered and analysed. So, ten uniform hazard spectra (UHS) have been calculated for the site of the building, i.e., Oakland (California, USA), by considering a C soil class. The UHS considered are depicted in Figure 5. The UHS have been obtained with reference to ten different exceedance probabilities equal to $1 \%, 2 \%, 4 \%, 5 \%, 7 \%, 10 \%$, $20 \%, 30 \%, 50 \%$, and $81 \%$ for a 50 years reference period. The 30 ground motion pairs have been scaled to match, as close as possible, their average (geometric mean) elastic spectrum with the corresponding reference UHS of the site. The UHS with exceedance probability equal to $5 \%$ in 50 years are the elastic spectrum corresponding to the collapse prevention limit state and adopted for the design of the two structures (with the respective $q$ values detailed before). For each one of the 10 seismic intensities, the time history analyses performed in OpenSEES provide the seismic response of the two different structures.

Furthermore, in order to derive the collapse fragility curve of the two buildings, an IDA procedure has been conducted on the FE models by considering the same seismic input already discussed. The criterion adopted to identify the collapse has been the attainment of at least one of the following conditions:

(i) Peak element rotation larger than the ultimate available rotation in structural elements

(ii) Peak interstorey drift ratio (IDR) in one direction $(X$ or $Y$ ) larger than $5 \%$

(iii) Numerical instability or absence of numerical convergence 
TABLE 1: Longitudinal rebars for beams and columns, as resulting from the seismic design for the two different approaches, i.e., single- $q$ and variable- $q$.

\begin{tabular}{|c|c|c|c|c|}
\hline \multirow{2}{*}{ Storey } & \multicolumn{2}{|c|}{ Beams } & \multicolumn{2}{|c|}{ Column } \\
\hline & Single- $q$ & Variable- $q$ & Single- $q$ & Variable- $q$ \\
\hline 1 & $6+6 \varnothing 20$ & $5+5 \varnothing 20$ & $20 \varnothing 20$ & $20 \varnothing 16$ \\
\hline 2 & $6+6 \varnothing 20$ & $7+7 \varnothing 22$ & $20 \varnothing 20$ & $20 \varnothing 22$ \\
\hline 3 & $6+6 \varnothing 20$ & $7+7 \varnothing 22$ & $20 \varnothing 20$ & $20 \varnothing 22$ \\
\hline 4 & $6+6 \varnothing 20$ & $7+7 \varnothing 22$ & $20 \varnothing 20$ & $20 \varnothing 22$ \\
\hline 5 & $6+6 \varnothing 20$ & $6+6 \varnothing 22$ & $20 \varnothing 20$ & $20 \varnothing 22$ \\
\hline 6 & $3+3 \varnothing 20$ & $4+4 \varnothing 22$ & $20 \varnothing 20$ & $20 \varnothing 22$ \\
\hline
\end{tabular}

Then, the main outcomes of the structural analyses have been adopted in the seismic loss analysis described in the following section. Figure 6(a) shows the median values of the peak interstorey drift ratio (IDR) for the various storeys for the two structures, obtained for the seismic intensity corresponding to the design-level intensity (i.e., $5 \%$ probability of exceedance in 50 years corresponding to the collapse prevention limit state). For the building designed with the variable- $q$, as expected, the IDR reached the highest values at the lower storeys of the structure (with values about $4 \%$ ), while is rather limited at the storeys from 3 to 6 with values of about $1 \%$. On the other side, the single- $q$ structure shows similar trend but with less marked values, in the range from $2 \%$ to $3 \%$, at the lower storeys (from 1 to 3 ) and values from $1 \%$ to $2 \%$ from storey from 4 to 6 . The trends substantially reflect the choice of the behaviour factor distributions and for the structure designed with the alternative $v q$ approach, which confirm that the highest displacement demand is limited to two storeys. In Figure 6(b), the mean peak floor acceleration values are reported for the two different structures, obtained for the seismic intensity corresponding to the design-level intensity. In this case, the maximum values for the two structures are substantially similar along the building elevation, with values slightly higher for the building designed with the single- $q$ approach. The outcomes of the structural analyses referred to other seismic intensities show similar trends. So, for the sake of brevity, they are not reported and further discussed here.

\section{Loss Assessment Analysis}

The loss assessment analyses have been performed with the Performance Assessment Calculation Tool (PACT) software [45] considering a probabilistic computation for the evaluation of the seismic losses.

In the analysis, a population model typical for hospital intended use has been selected in accordance with FEMA [21]. In the population model, the peak occupancy ratio has been assumed equal to 8 people $/ 100 \mathrm{~m}^{2}$ for each storey [39]. A unitary construction cost (UCC) equal to $2000 \$ / \mathrm{m}^{2}$ has been adopted. This leads to a total construction cost (TCC) for the building equal to 10.8 million $\$$. The total replacement cost (TRC), including demolition and waste disposal costs, has been assumed equal to 12 million $\$$. This value has been assumed to be equal to the building replacement cost.
Lastly, the structural performance results in terms of peak interstorey drift, peak floor acceleration, and peak residual drift - the outcomes of the time history analyses for the 10 seismic intensities discussed before-have been considered as input data in the software.

A statistical Monte Carlo simulation has been conducted considering 600 realizations. In this methodology, the building performance is expressed as the probable damage and the resulting consequences associated with earthquake shaking. Figure 7 shows the hazard curve for the site of Oakland (California, USA), assuming a C soil class [46]. In the paper, the following performance measures [21] have been considered and calculated:

(1) Number of Fatalities. Loss of life occurring within the building envelope during or in the aftermath of the event.

(2) Number of Injured People. People with serious injury occurring within the building envelope and requiring hospitalization.

(3) Repair Cost. The cost, in dollars, necessary to restore a building to its pre-earthquake condition or, in the case of total loss, to replace the building with a new structure of similar construction. Repair costs include consideration of all necessary construction activities to return the damaged components to their pre-earthquake condition. Repair actions assume repair or replacement in-kind and do not include work associated with bringing a nonconforming installation or structure into compliance with newer criteria. Repair costs are based on the repair measures including removal or protection of contents adjacent to the damaged area; shoring of the surrounding structure (if necessary); protection of the surrounding area (e.g., from dust and noise) with a temporary enclosure; removal of architectural and mechanical, electrical, and plumbing systems, as necessary, to obtain access for the repair; procurement of new materials and transport to the site; conduct of the repair work; replacement of architectural and mechanical, electrical, and plumbing systems, as necessary; and clean-up and replacement of contents. The repair cost is usually expressed as a percentage of the TCC. 


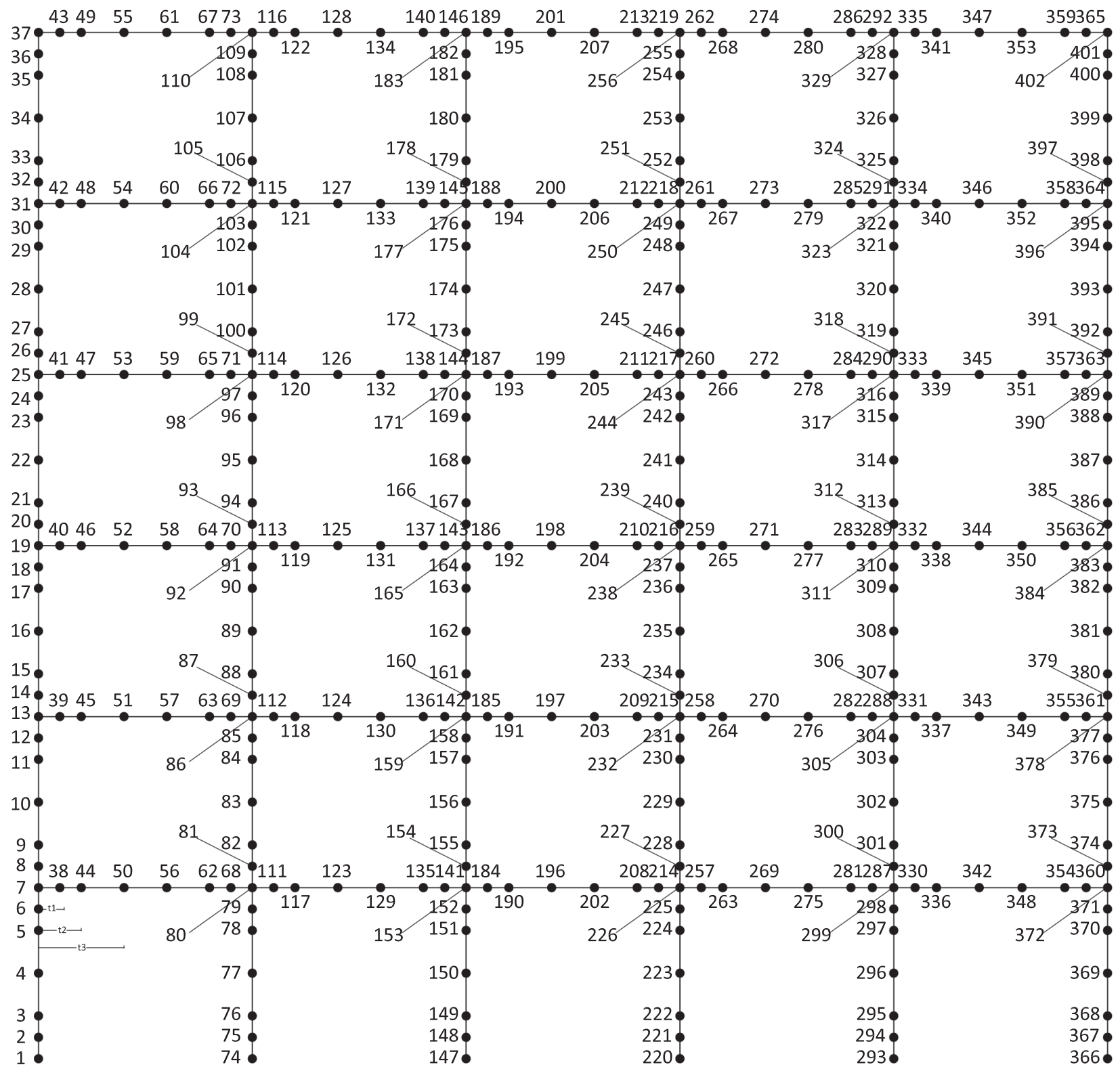

FIGURE 4: Lateral view of a perimeter frame of the FE model adopted in the nonlinear analysis for the structural seismic response evaluation.

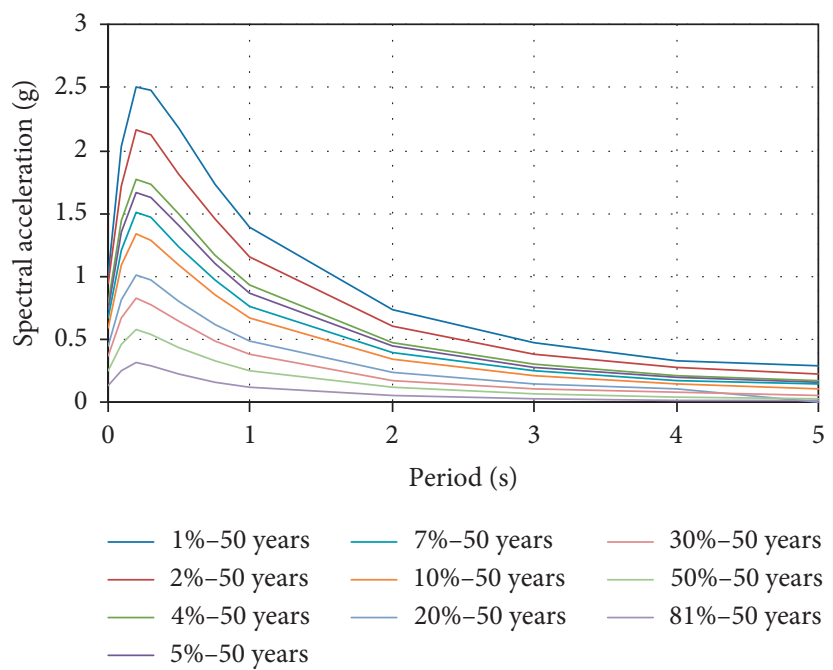

FIGURE 5: Uniform hazard spectra calculated for the site of Oakland (California, USA). 
(4) Repair Time. The time, in weeks, necessary to repair a damaged building to its pre-earthquake condition. The estimation of the repair time is calculated in PACT starting from the total replacement time considered here, equal to 730 days, and the maximum number of workers, involved in the repair operations, assumed equal to 25 . The repair time is usually expressed as a percentage of the total replacement time.

The performance groups (for definition see [21]) for the structural elements considered in the loss assessment analysis have been given as follows:

(1) RC moment-resisting frames

(2) RC link beams

(3) RC slabs and plates of the diaphragms

The performance groups (for definition see [21] for nonstructural elements, equipment, and systems considered in the loss assessment analysis have been as follows:

(1) Exterior walls

(2) Exterior glazing systems

(3) Nonstructural floor elements (e.g., flooring and insulation)

(4) Roof tiles, masonry chimneys, and parapets

(5) Interior partitions

(6) Ceilings

(7) Stairs

(8) Elevators

(9) Mechanical equipment and distribution systems (e.g., chillers, cooling towers, air handling units, piping, and ducting)

(10) Electrical equipment and distribution systems (e.g., transformers, switchgear, distribution panels, battery racks, recessed lighting, and pendant lighting)

(11) Fire protection and prevention system

(12) Access floors, workstations, bookcases, filing cabinets, and storage racks

The fragility functions and the consequence functions implemented in PACT have been adopted for the performance groups listed above. According to the FEMA [21], the selected stochastic variables/choices, which change at every simulation of the Monte Carlo procedure, have been given as follows:

(1) The seismic intensity measure depending on the hazard curve of the site

(2) The condition "collapsed building" or "not collapsed building" based on the seismic fragility curve at collapse of the building

(3) The condition "repairable building" or "not repairable building" based on the building repair fragility based on residual drift ratio (see [21])
(4) The moment of the seismic events so to consider different occupancy ratio during 24 hours

For the two structural solutions, the same performance groups have been selected in PACT. It is to clarify that, for seismic intensity levels higher than the seismic intensity level adopted for the design of the two structures (i.e., the collapse prevention limit state corresponding to a probability of exceedance of $5 \%$ in 50 years), the FE numerical models have assessed, in some cases, the attainment of a collapse condition (i.e., peak element rotation larger than ultimate available rotation or peak interstorey drift ratio (IDR) in one direction larger than $5 \%$ or numerical instability or absence of numerical convergence). Therefore, as expected, for the seismic intensity levels corresponding to probability of exceedance of $1 \%, 2 \%$, and $4 \%$ in 50 years, the high nonlinear behaviour attained by the FE model of the two structures could provide a slightly less accurate assessment of the building seismic response [33] since this last could be influenced by the hysteretic laws adopted in the FE model [47]. In order to reduce to the minimum the possible effects of numerical instability of the model for some ground motions, the median values of the seismic response have adopted as central values in the Monte Carlo simulation (instead of the mean values usually more influenced by outlier presence) and a proper number of seismic intensity levels, as suggested in FEMA [21], have been assumed.

5.1. Intensity-Based Loss Analyses. The comparison of the seismic performance of the two structures-in terms of number of fatalities, number of injured people, repair cost, and repair time-has been set for each seismic intensity considered in the study (i.e., the levels corresponding to the probabilities of exceedance of $81 \%, 50 \%, 30 \%, 20 \%, 10 \% 7 \%$, $5 \%, 4 \%, 2 \%$, and $1 \%$ over a period of 50 years).

As a first outcome, Figures 8(a) and 8(b) report the scenario assessments of the expected number of fatalities and number of injured people, for the two structures and for the 10 seismic intensity. It can be derived that the adoption of the variable- $q$ design approach provides a reduction of the expected consequences for the building occupants. This is valid for all seismic intensities investigated.

In Figure 8(c), the trend of the total repair cost is reported with reference to the ten levels of seismic intensity described. As expected, with the increase in the seismic intensity, the repair cost increases. An interesting aspect to be highlighted is that the building designed with variable- $q$ values results in repair costs always lower than the building designed with the single- $q$ factor. This means that the alternative approach considering a localized damage for the case study structure, if properly calibrated, can provide a solution with a lower impact in terms of economic losses, compared with the structure designed with the traditional approach based on distributed damage.

Finally, with regard to the total repair time, reported in Figure $8(\mathrm{~d})$, the outcomes are similar for the two structures, indeed the expected repair time is practically the same for 


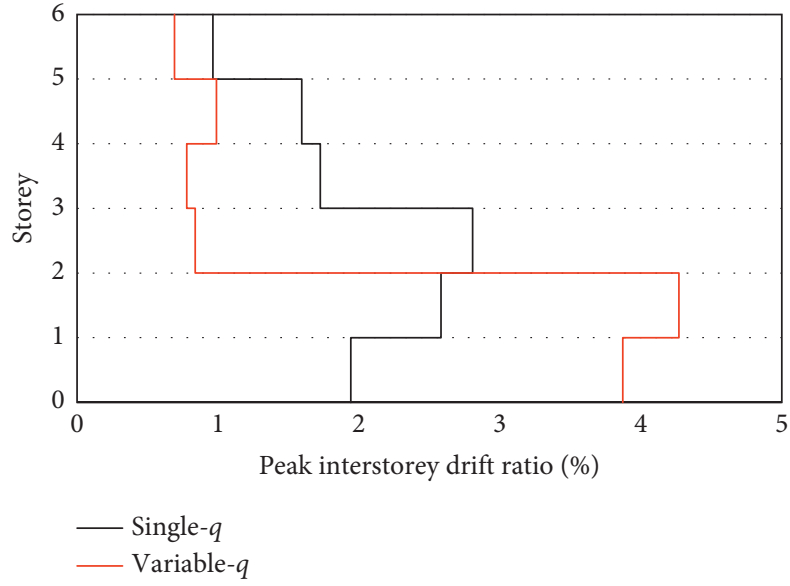

(a)

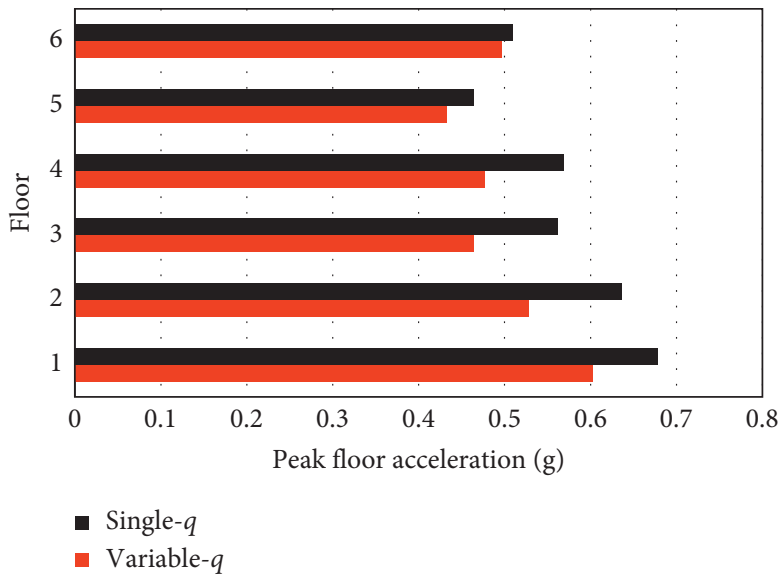

(b)

Figure 6: Main results of the nonlinear time history analyses for a 5\% probability of exceedance in 50 years for the two different design solutions: single- $q$ and variable- $q$ : (a) median peak interstorey drift ratio values; (b) median peak floor acceleration values.

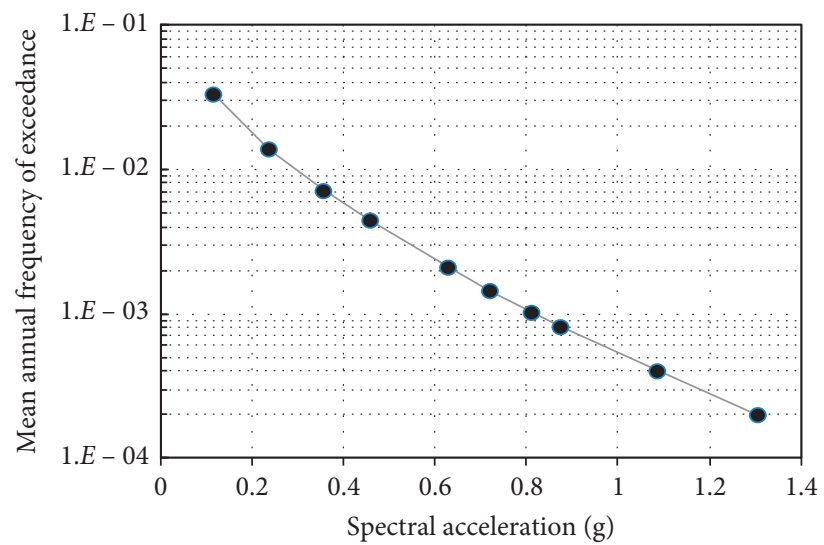

FIgURE 7: Hazard curve for the site of Oakland (California, USA) assuming a C class for soil.

each seismic intensity. In the ordinate of the graph, the repair time expressed in days refers to the days of work, referring to the hypotheses detailed above, and does not consider the time to obtain licenses, authorizations, and the time for the planning and design phases.

5.2. Time-Based Loss Analyses. The time-based loss analyses have been conducted considering the hazard curve assumed for the site of the building, located in Oakland (California, USA) and shown in Figure 7, where the black dots in the curve represent the ten intensity levels considered in the work.

The results reported below show the comparison of the main outcomes of the loss assessment analyses performed on the two structures designed with different approaches. In Figure 9, the graphs of the annual probability (in ordinate) to reach the prescribed values of total repair cost, total repair time, number of injured people, and number of fatalities (in abscissa) are displayed. The different colours graphically indicate the contribution of the ten different intensities to the annual probability of exceedance values. As shown in various images in Figure 9, the seismic events with lowmoderate intensity (e.g., intensities 1, 2, 3, 4, and 5 corresponding to probability of exceedance equal to $81 \%, 50 \%$, $30 \%, 20 \%$, and $10 \%$ for a period of 50 years) play an important role. Indeed, even if they are not able to reach the level of loss of the extreme seismic events (the ones with lower probability of exceedance), they have a higher annual probability of occurrence. Therefore, in general, these events have corresponding areas (i.e., expected losses over the period considered) that are not negligible and comparable to those of the severe-high seismic intensity levels (e.g., intensities $6,7,8,9$, and 10 corresponding to probability of exceedance equal to $7 \%, 5 \%, 4 \%, 2 \%$, and $1 \%$ for a period of 50 years). This is a very important aspect because it confirms that the seismic performance of a building, on a long reference period, depends not only on the behaviour of the structure under extreme events but also on the seismic response under low-moderate earthquakes. As far as the comparison of the two structures is concerned, the outcomes generally show analogous trends with annual probability values slightly higher for the case of single- $q$ design approach. 
The main results of the time-based loss assessment analyses are summarized in Tables 2 and 3. Table 2 collects the annual average values of the four loss indicators used in this paper, for both structures. For a fast and clearer comparison, the annual saving that the adoption of the alternative approach could allow to reach is also reported.

Analogous results are reported in Table 3 but with reference to a 50 years period. The values in Table 3 highlight how the alternative design criterion proposed $(v q)$ allows a (positive) saving for all performance measures considered in the comparison in this paper. Nowadays, there is not a universally accepted performance measure for the comparison of the seismic performance of different buildings, but anyway, for the specific case study, all measures considered provide a saving (loss reduction) if the approach based on variable- $q$ factor is adopted in the design. Moreover, the loss reduction in some cases is not negligible. Indeed, the difference in the performances shown by the two structures is variable, depending on the measure considered, but the lowest loss values are always obtained in the $v q$ approach. The saving values range from approximately $10 \%-$ $12 \%$ for total repair time and total repair cost, to about $41 \%-$ $43 \%$ for the number of injured people and number of fatalities.

Therefore, following these results, it can be stated that the alternative design procedure proposed in this paper, if properly adapted and calibrated on the basis of the required damage mechanism, could be advantageous from all points of view. The reduction of the consequences to building occupants with the $v q$ approach is remarkable, with an expected reduction (saving) higher than $40 \%$ in the number of expected fatalities and injuries during the service life of the building (assumed equal to 50 years), compared with the $1 q$ approach results.

A disaggregation analysis of the expected loss for each of the six storeys of the building has been set for the two approaches. The graphs in Figure 10 have the storey number on the ordinate and the expected loss measure in the abscissa. The storey loss disaggregation allows understanding of which storeys are more vulnerable and provide the highest expected loss values, to drive, for example, future actions prone to reduce the expected losses or increase the seismic performance of the building.

Figure 10 shows that, generally, the building designed with the single- $q$ approach to distribute the damage among the storeys has rather uniform loss values or decreases almost linearly along the building elevation. On the other hand, the building designed with the alternative approach proposed here concentrates the losses, as expected, at the first two storeys (those designed with the highest behaviour factor value). For the case study building under study, it is possible to state that the $1 q$ approach results in a higher expected loss with respect to the buildings designed with the alternative approach concentrating the damage in a few storeys. It is to highlight that, for this second approach, the general increase in loss at first and second storeys is widely balanced by the loss reduction at the upper floors, showing that globally the structure designed with the $v q$ approach has better seismic performance.
5.3. Time-Based Loss Analyses with Occupants Redistribution. Looking at the storey disaggregation regarding the number of injured people and number of fatalities, further consideration can be derived. In fact, the structure designed with the alternative approach provides the interesting possibility to operate a redistribution of building occupants in order to minimize the seismic consequences on people so reducing the human life loss. Indeed, at this point, it is possible to consider the result of the seismic loss assessment as a tool for supporting the decision-making phase, to evaluate different alternative risk-reduction strategies. It is well-known that each hospital is comprised of a wide range of services and functional units. These include diagnostic and treatment functions, such as clinical laboratories, imaging, emergency rooms, and surgery; hospitality functions, such as food service and housekeeping; and fundamental inpatient care or bed-related function [39]. Taking advantage of this complexity and of the contemporary presence of different functions in the same building, it could be an opportunity to assume, in the design phase, that functional units involving the highest people presence will be located on specific storeys. So, just to provide the reader a possible application and example, we assume to operate a redistribution of the maximum building occupants (i.e., 432 people) by attributing an occupancy ratio of 10 people $/ 100 \mathrm{~m}^{2}$ for the storeys from 3 to 6 and occupancy ratio equal to 4 people $/ 100 \mathrm{~m}^{2}$ for storeys 1 and 2 (see Figure 11). This operation, that globally does not change the original maximum building occupants, could be achieved by differentiating the functions for the various storeys. By introducing this modification only (i.e., different people distribution along with the storeys) in the Monte Carlo simulation conducted for the structure designed with variable- $q$ approach, the number of fatalities is reduced up to the $16 \%$ with respect to the results achieved previously for the same structural situation but with people equally distributed on the storeys. The option to change the distribution of people in the storeys of the hospital does not provide benefits in the case of structure designed adopting the single- $q$ approach because the number of fatalities and injured people is almost uniform along the building height. The possibility to select the $q$ values on the basis of the seismic performance measure to optimize represents an interesting novel solution for buildings designed with the alternative approach. Clearly, the decision to concentrate higher people presence at the higher storeys should deserve some consideration from a more general point of view, taking into account all possible risk sources for occupants (e.g., fire risk). Of course, this aspect is out of the scope of the paper.

\section{Evaluation of the Soil Influence on the Building Seismic Performance}

A further investigation is proposed herein to evaluate the influence of the soil class on the seismic performance of the building. As already stated before, the previous analyses have been conducted assuming a $\mathrm{C}$ soil class. To establish the influence of the soil class on the building seismic performance, two further soil classes have been selected: one with 


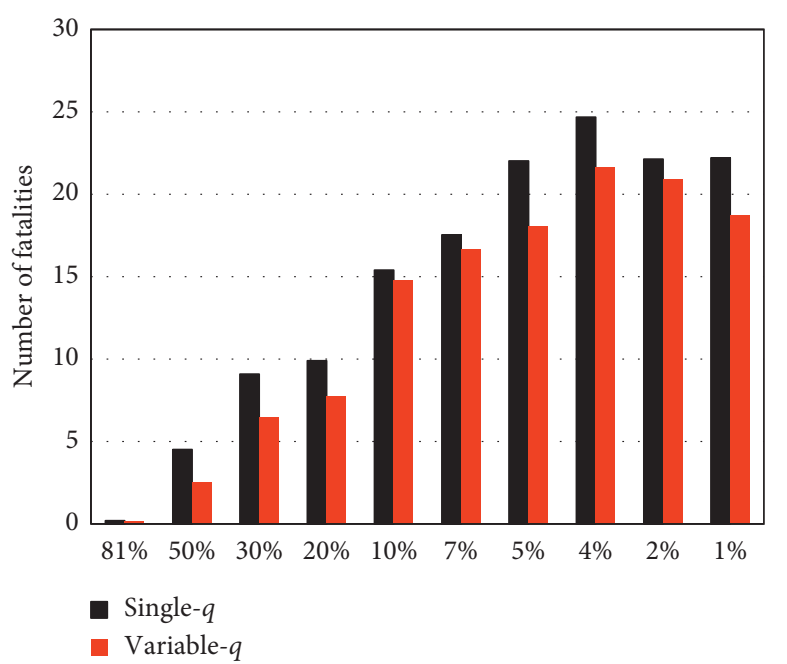

(a)

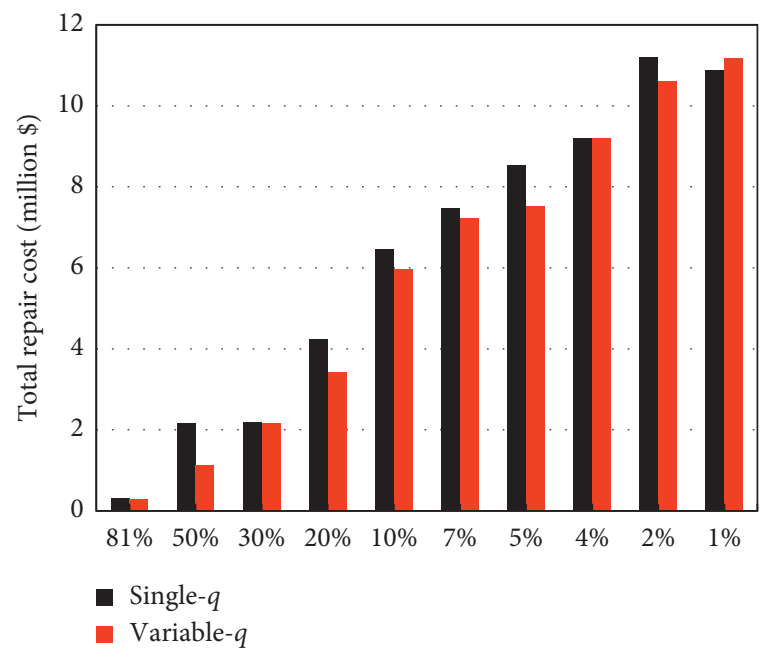

(c)

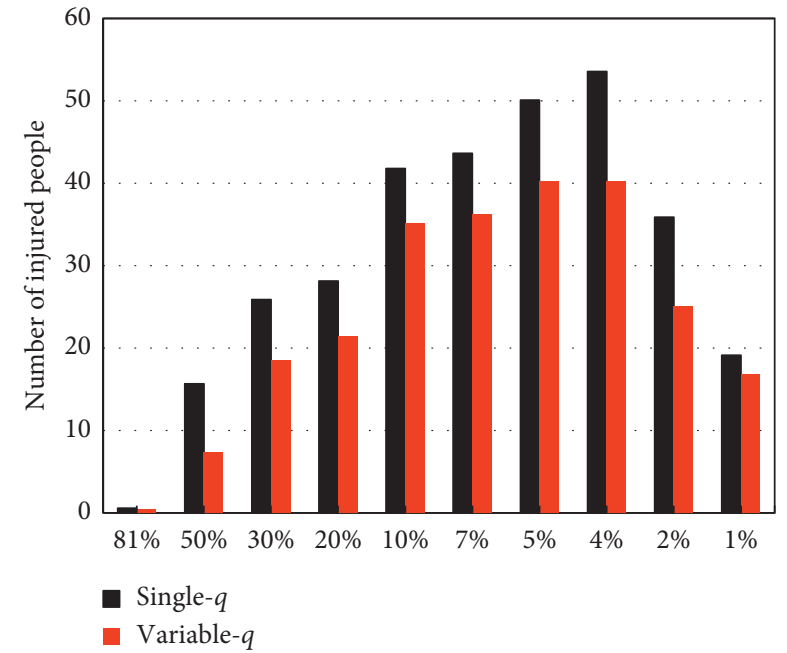

(b)

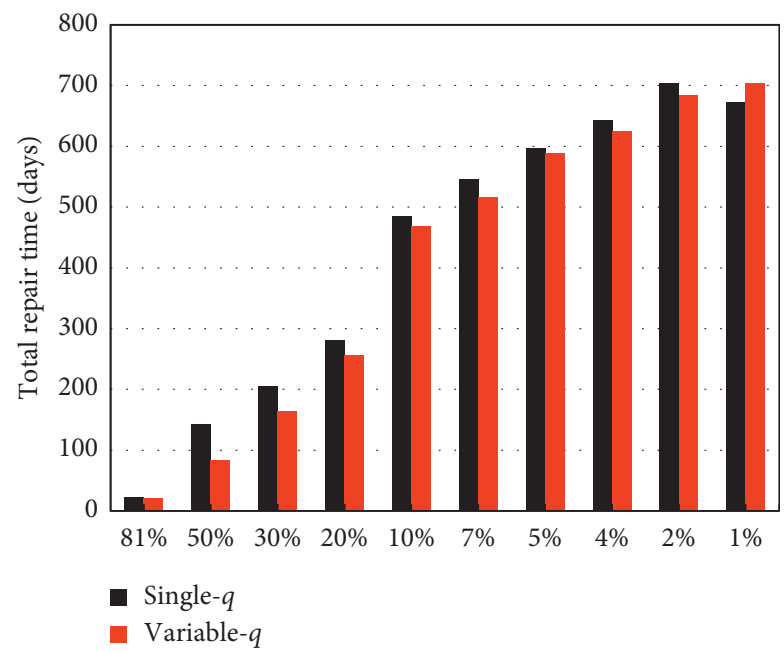

(d)

Figure 8: Comparison of the seismic performance of the two structures: (a) number of fatalities; (b) number of injured people; (c) total repair cost; (d) total repair time.

better mechanical properties corresponding to lower seismic acceleration (B class) and the other with worse mechanical properties resulting in higher seismic acceleration (D class).

Figure 12 shows the comparison between the different hazard curves referred to the different soil classes selected for the comparison as obtained by USGS [46]. It should be noted that the adoption of a better soil class (B soil class) corresponds to a hazard curve positioned on the left of the original hazard curve of the $\mathrm{C}$ soil class. This essentially leads, for a specific value of spectral acceleration, to a lower mean annual frequency of exceedance values (i.e., reduce the probability to observe, in the reference time, a specific spectral acceleration value). Conversely is in the case of D soil class.

Thus, the two hazard curves have been implemented in the PACT software, to perform the assessment of expected loss for the different soil classes. The results obtained with reference to a time span of one year are summarized in Table 4 . The rows "Relative difference" in the table show (in percentage) the difference between the loss value obtained by the single- $q$ approach and the loss value obtained for the variable- $q$ approach, all divided by the value obtained from the single- $q$ approach. The positive values (+) of the "Relative difference" collected in Table 4 underline how, for every soil class, the structure designed with a variable- $q$ approach is characterized by better seismic performances than the structure designed with the traditional approach, for every loss measure considered. Small variations from class to class are present in the "Relative difference" values, but anyway the variable- $q$ approach seems to provide significative convenience for all the three hazard curves. This furtherly confirms that the approach to consider different behaviour factors for the different storeys of a structure for some building typologies could be convenient independently from the site and the local seismic hazard. Lastly, as a further confirmation, it is to highlight that for D soil class, all mean annual expected losses increase with respect to $\mathrm{C}$ soil class and, at the opposite, they decrease significantly by considering B soil class. 

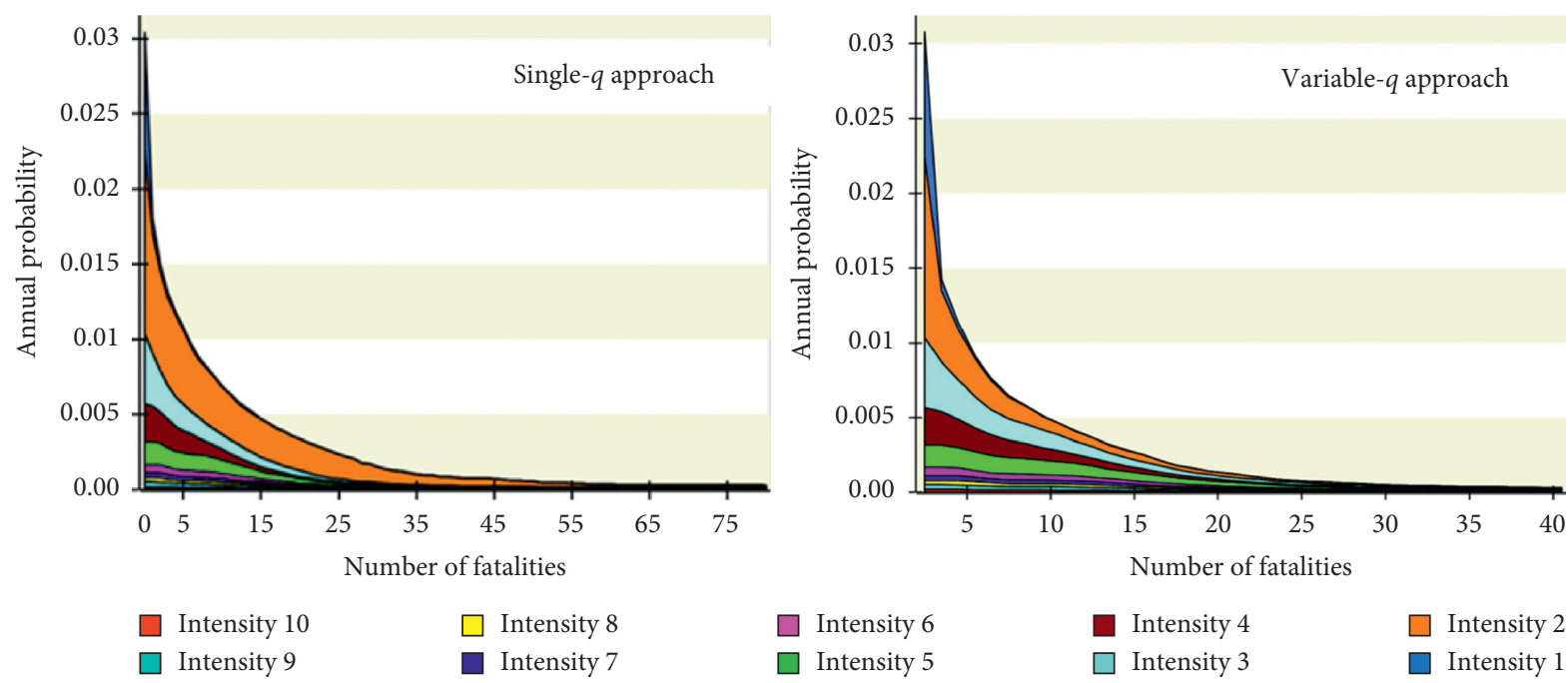

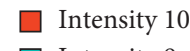

$\square$ Intensity 9

$\square$ Intensity 8

$\square$ Intensity 7

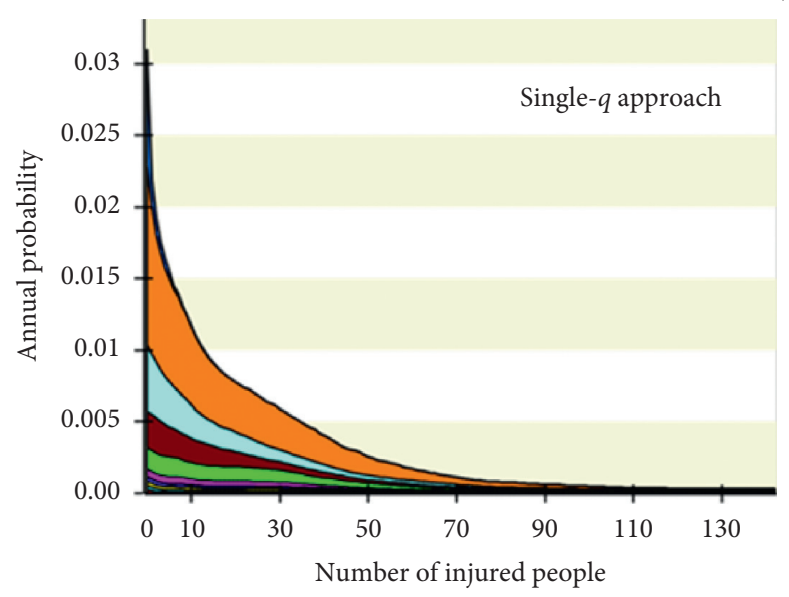

$\square$ Intensity 10

$\square$ Intensity 9

$\square$ Intensity 8

$\square$ Intensity 7

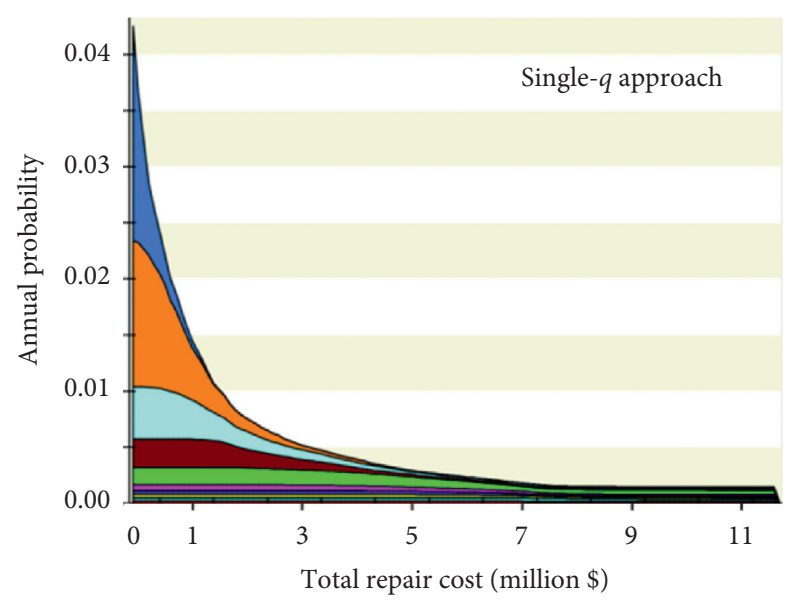

$\square$ Intensity 10

$\square$ Intensity 9 $\square$ Intensity 8

$\square$ Intensity 7

a)

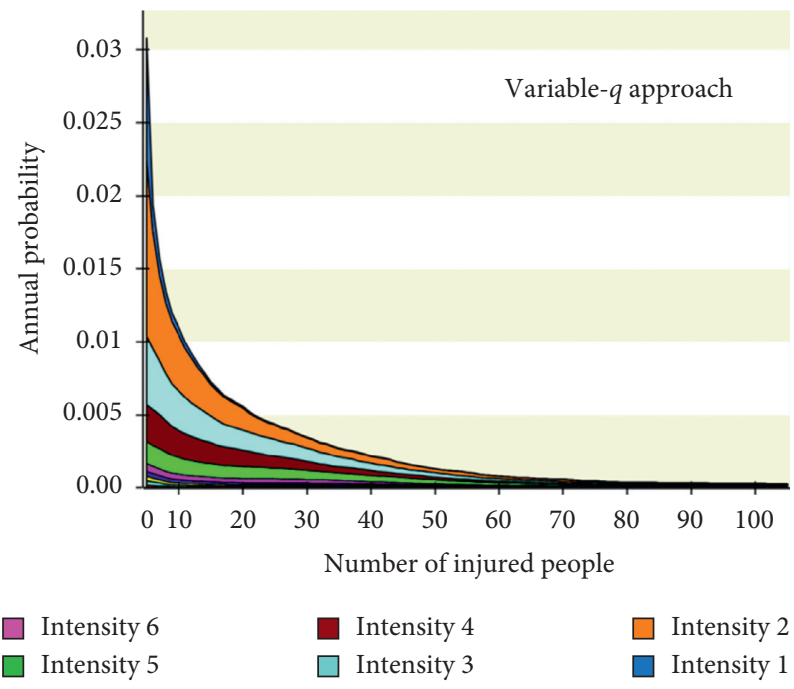

(b)

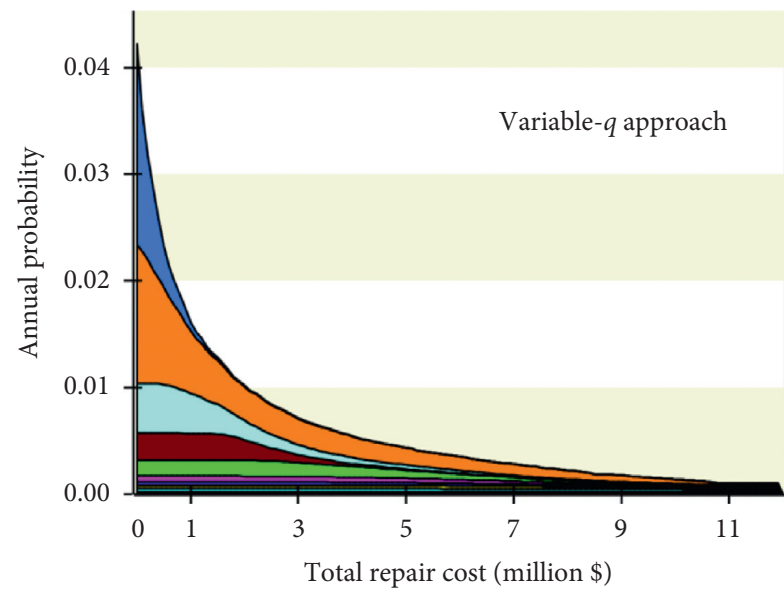

Intensity 6

Intensity 5

$\square$ Intensity 4

Intensity 2

(c)

Figure 9: Continued. 

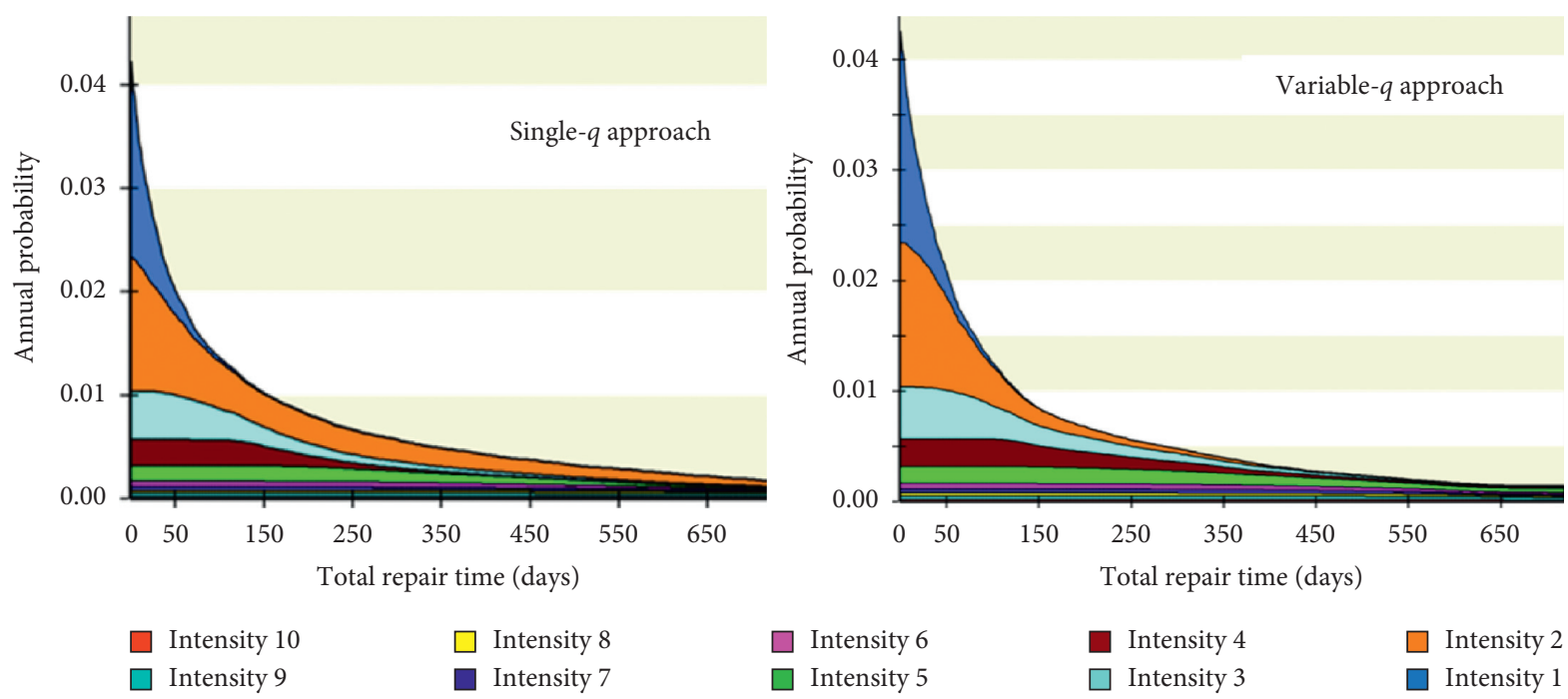

(d)

Figure 9: Comparison of the main results of the time-based loss analyses for the two structures, designed with single- $q$ and variable- $q$ approaches, in terms of (a) number of fatalities, (b) number of injured people, (c) total repair cost, and (d) total repair time.

TABle 2: Time-based loss assessment analyses results referred to 1 year. Difference is obtained as subtraction between the single- $q$ approach value and variable- $q$ approach value.

\begin{tabular}{lccc}
\hline Performance measure & Single- $q$ approach & Variable- $q$ approach & Difference (percentage) \\
\hline Number of fatalities & 0.24 & 0.14 & $+0.10(+41.6 \%)$ \\
Number of injured people & 0.60 & 0.34 & $+0.26(+43.3 \%)$ \\
Total repair cost $(\$)$ & 72748.0 & 63769.0 & $+8979.0(+12.3 \%)$ \\
Total repair time (days) & 5.36 & 4.78 & $+0.58(+10.8 \%)$ \\
\hline
\end{tabular}

Table 3: Time-based loss assessment analyses results referred to 50 years. Difference is obtained as subtraction between the single- $q$ approach value and variable- $q$ approach value.

\begin{tabular}{lccc}
\hline Performance measure & Single- $q$ approach & Variable- $q$ approach & Difference (percentage) \\
\hline Number of fatalities & 30 & 17 & $+13.0(+43.3 \%)$ \\
Number of injured people & 12 & 7 & $+5.0(+41.7 \%)$ \\
Total repair cost (million $\$)$ & 3.637 & 3.188 & $+0.449(+12.3 \%)$ \\
Total repair time (days) & 268 & 239 & $+29.0(+10.8 \%)$ \\
\hline
\end{tabular}

\section{Final Remarks}

The paper presents the results of the seismic performance assessment of a new 6-story hospital building, with RC frames seismically designed following an alternative capacity design approach, proposed here. In order to set a comparison, the structural elements of the buildings have been also designed following the traditional capacity-based approach. The traditional approach, following the usual practice of capacity design, considers only one single value for the behaviour factor $q$ for the design of a structure able to distribute the seismic damage among the floors (single- $q$ design approach). The alternative approach, instead, considers the possibility to select differentiated behaviour factor values for the different storeys (variable- $q$ approach). The flow chart of the new procedure proposed herein has been provided and discussed in the paper.

By means of the seismic loss assessment methodology, the comparison of the seismic performance of the two structures has been set in terms of four different performance measures: number of fatalities, number of injured people, total repair cost, and total repair time resulting from both intensity-based loss analyses and time-based loss analyses of the building.

The outcomes of the loss analyses suggest that the adoption of the alternative design approach, calibrated to provide the desired damage mechanism during a seismic event, is advantageous for all performance measures considered in the study. 


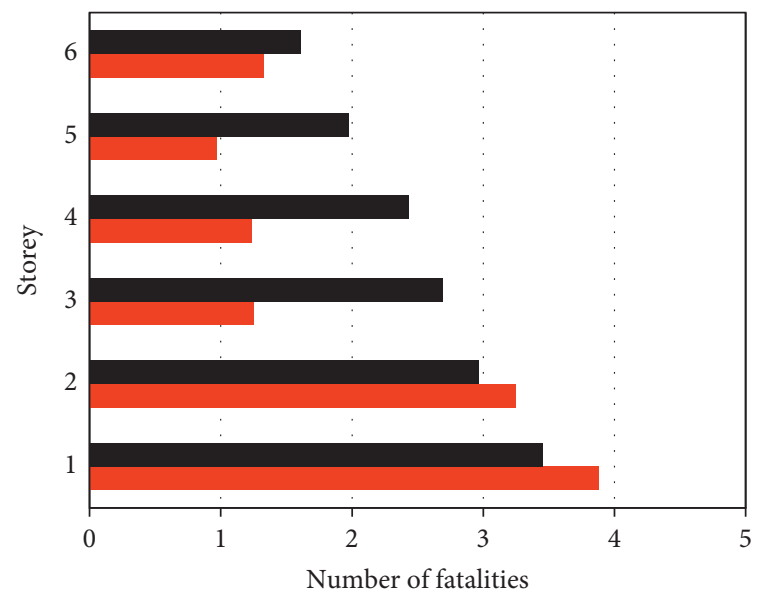

- Single- $q$

- Variable- $q$

(a)

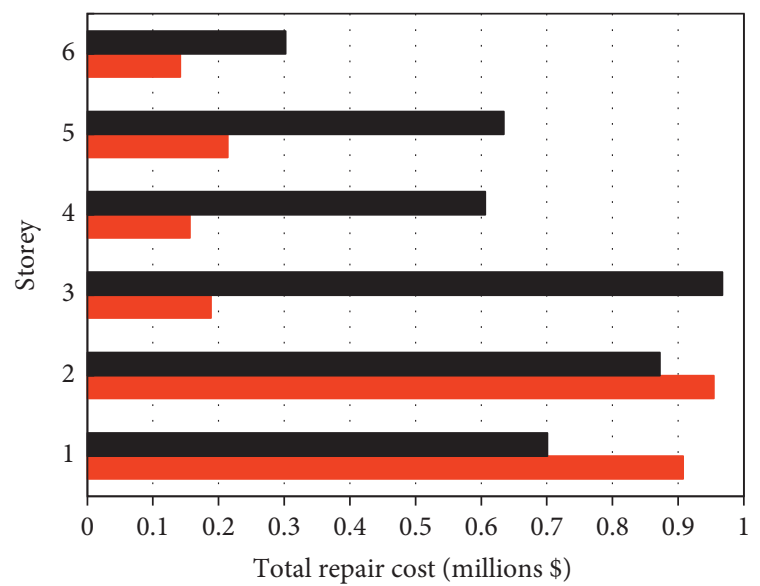

- Single- $q$

- Variable- $q$

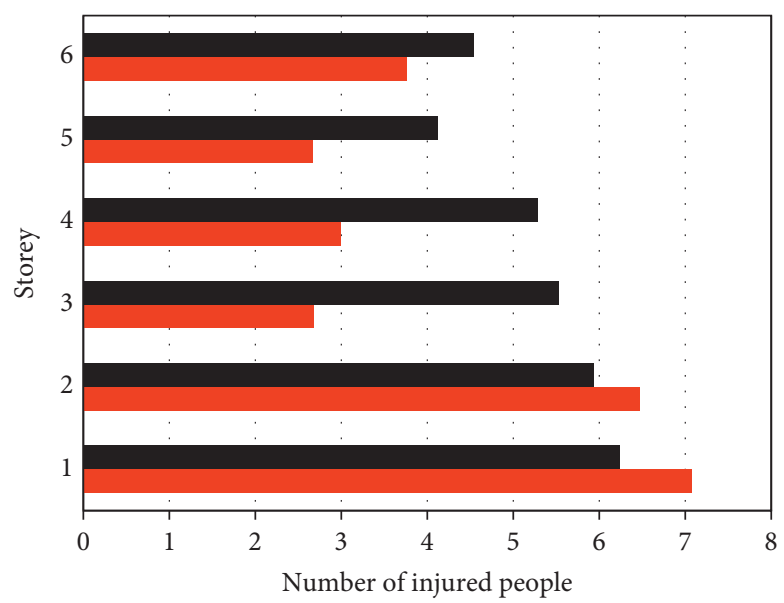

- Single- $q$

- Variable- $q$

(b)

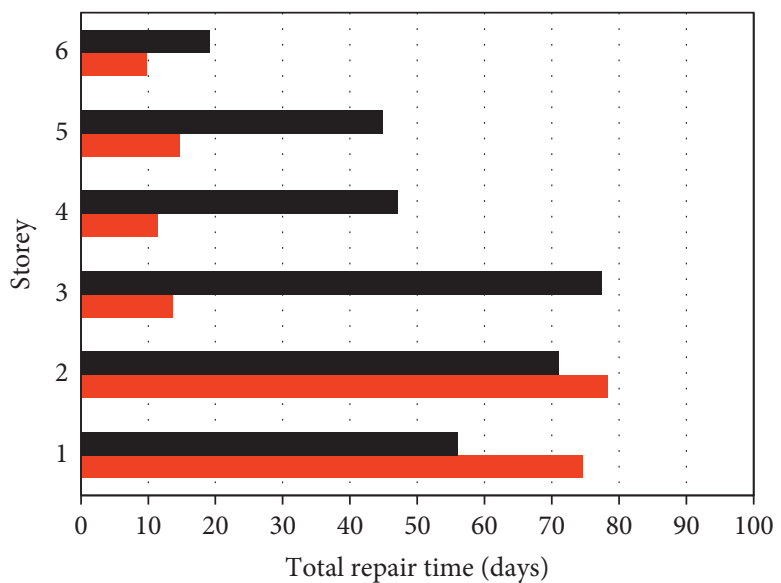

- Single- $q$

- Variable- $q$

(c)

(d)

FIGURE 10: Comparison of the expected losses for the various building storeys of the two structures: (a) number of fatalities; (b) number of injured people; (c) total repair cost; (d) total repair time.

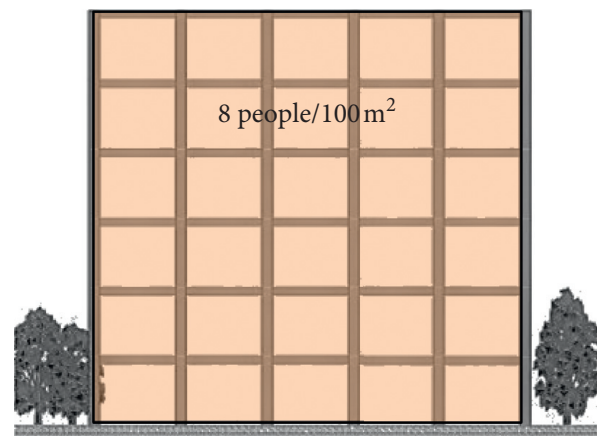

(a)

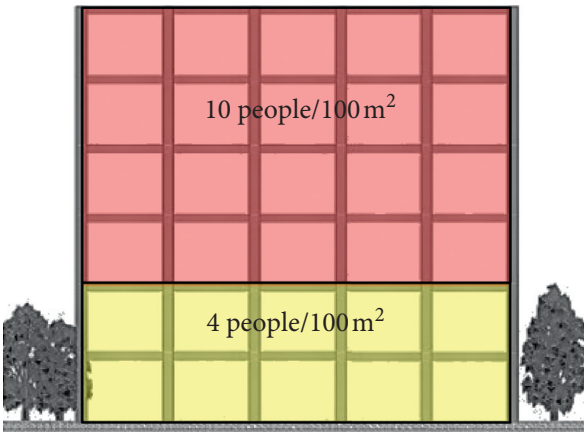

(b)

FIGURE 11: Building occupants distributions at the various storeys: (a) original distribution assumed in the performance assessment analyses; (b) redistribution operated in the Section 5.3. 


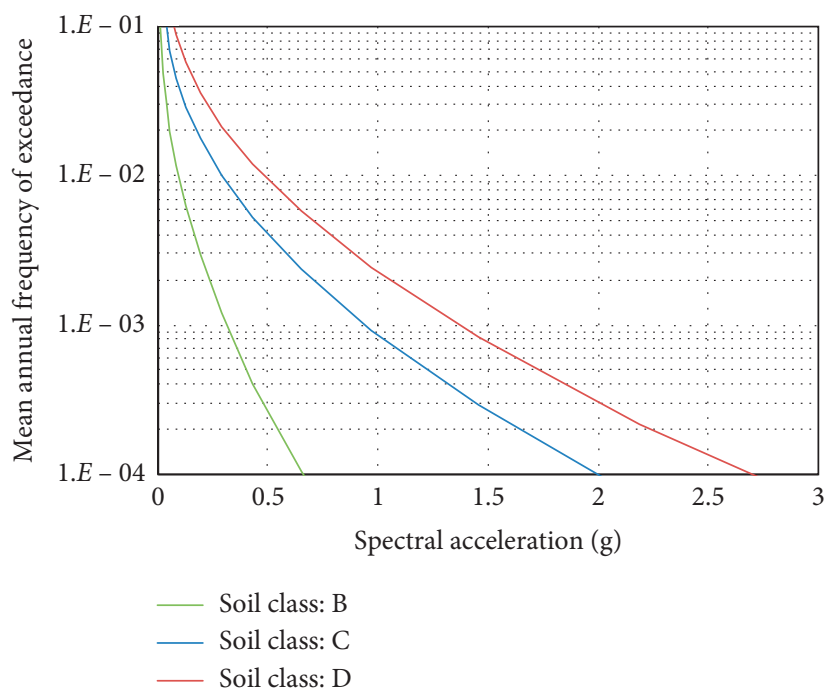

Figure 12: Hazard curve for the three different soil classes (B, C, and D) adopted in the comparison in Section 6.

TABLE 4: Evaluation of the influence of the soil class on the seismic performance of the building. Comparison between the two design approaches (single- $q$ and variable- $q$ ) for the different soil classes considered.

\begin{tabular}{|c|c|c|c|c|}
\hline Performance measure & Design approach & B soil class & C soil class & D soil class \\
\hline \multirow{3}{*}{ Number of fatalities } & Single- $q$ & 0.17 & 0.251 & 1.41 \\
\hline & Variable- $q$ & 0.099 & 0.144 & 0.848 \\
\hline & Relative difference & $+41.76 \%$ & $+42.63 \%$ & $+39.86 \%$ \\
\hline \multirow{3}{*}{ Number of injured people } & Single- $q$ & 0.44 & 0.63 & 3.41 \\
\hline & Variable- $q$ & 0.30 & 0.35 & 2.43 \\
\hline & Relative difference & $+31.82 \%$ & $+44.20 \%$ & $+28.74 \%$ \\
\hline \multirow{3}{*}{ Total repair cost (\$) } & Single- $q$ & 44755 & 74632 & 397712 \\
\hline & Variable- $q$ & 36816 & 62973 & 342561 \\
\hline & Relative difference & $+17.74 \%$ & $+15.62 \%$ & $+13.87 \%$ \\
\hline \multirow{3}{*}{ Total repair time (days) } & Single- $q$ & 3.39 & 5.48 & 29.68 \\
\hline & Variable- $q$ & 2.83 & 4.59 & 25.84 \\
\hline & Relative difference & $+16.52 \%$ & $+16.24 \%$ & $+12.94 \%$ \\
\hline
\end{tabular}

Indeed, even if the difference in the performances calculated for the two structures is variable from a performance measure to another, the loss reduction ranges from approximately $10 \%-12 \%$ for total repair time and total repair cost to about $41 \%-43 \%$ for the number of injured people and number of fatalities. Thus, the alternative design approach proposed here, for the case study investigated in this work, provides a remarkable reduction of the expected impact on human lives loss during the service life of the building.

Finally, an investigation aiming to evaluate the influence of the soil class on the seismic performance of the structures has confirmed that the adoption of the variable- $q$ design approach proposed here is convenient independently from the local hazard of the site. Indeed, for all the cases investigated, the structure designed with the variable- $q$ approach showed lower loss values than the structure designed with the traditional single- $q$ approach.

It is worth noticing that the results reported in the paper represent only a preliminary outcome of the application of the alternative approach proposed here even though the procedure seems particularly promising under the different points of view examined. Further and necessary investigations to apply the approach to different test bed structures will be object of future and deeper research studies in this field.

\section{Data Availability}

No data were used to support this study.

\section{Conflicts of Interest}

The authors declare that they have no conflicts of interest.

\section{References}

[1] J. Jia, Modern Earthquake Engineering, Springer-Verlag, Berlin Heidelberg, Germany, 2017.

[2] ASCE (American Society of Civil Engineers), Minimum Design Loads and Associated Criteria for Buildings and Other Structures, ASCE/SEI 7-16, ASCE, Reston, VA, USA, 2017. 
[3] CEN (European Committee for Standardization), General Rules, Seismic Actions and Rules for Buildings. Eurocode 8, European Committee for Standardization, Brussels, Belgium, 2005.

[4] FEMA (Federal Emergency Management Agency), NEHRP Prestandard and Commentary for the Seismic Rehabilitation of Buildings, FEMA 356, FEMA, Washington, DC, USA, 2000.

[5] NTC (Norme Tecniche Costruzioni), Italian Building Code, Ministerial Decree 17/01/2018, NTC, Rome, Italy, 2018.

[6] NZS (New Zealand Standards), Structural Design Actions, NZS 1170, New Zealand Standards, Wellington, New Zealand, 2004.

[7] S. Pampanin, C. Christopoulos, and M. J. Nigel Priestley, "Performance-based seismic response of frame structures including residual deformations. Part II: multi-degree of freedom systems," Journal of Earthquake Engineering, vol. 7, no. 1, pp. 119-147, 2003.

[8] IRMI (International Risk Management Institute), 2021, https://www.irmi.com.

[9] L. Hofer, M. A. Zanini, F. Faleschini, and C. Pellegrino, "Profitability analysis for assessing the optimal seismic retrofit strategy of industrial productive processes with business-interruption consequences," Journal of Structural Engineering, vol. 144, no. 2, Article ID 04017205, 2018.

[10] M. Bovo, A. Barbaresi, D. Torreggiani, and P. Tassinari, "Collapse and damage to vernacular buildings induced by 2012 Emilia earthquakes," Bulletin of Earthquake Engineering, vol. 18, no. 3, pp. 1049-1080, 2020.

[11] R. Han, Y. Li, and J. van de Lindt, "Seismic loss estimation with consideration of aftershock hazard and post-quake decisions," ASCE-ASME Journal of Risk and Uncertainty in Engineering Systems, Part A: Civil Engineering, vol. 2, no. 4, Article ID 04016005, 2016.

[12] S. A. Mahin, V. Terzic, and C. Nagy, "Using performancebased earthquake evaluation methods to assess the relative benefits of different structural systems," in Proceedings of the 9th International Conference on Urban Earthquake Engineering, Tokyo, Japan, March 2012.

[13] I. Nuzzo, N. Caterino, and S. Pampanin, "Seismic design framework based on loss-performance matrix," Journal of Earthquake Engineering, pp. 1-21, 2020.

[14] T. J. Sullivan, D. P. Welch, and G. M. Calvi, "Simplified seismic performance assessment and implications for seismic design," Earthquake Engineering and Engineering Vibration, vol. 13, no. S1, pp. 95-122, 2014.

[15] OES (California Office of Emergency Services), Vision 2000: Performance Based Seismic Engineering of Buildings, Structural Engineers Association of California, Sacramento, CA, USA, 1995.

[16] S. Otani, "Development of performance-based design methodology in Japan," in Seismic Design Methodologies for the Next Generation of Codes, P. Fajfar and H. Krawinkler, Eds., A. A. Balkema, Rotterdam, Netherlands, 1997pp. 59-68, Proceedings of the International Conference at Bled, Slovenia.

[17] C. D. Poland and D. B. Hom, "Opportunities and pitfalls of performance-based seismic engineering," in Seismic Design Methodologies for the Next Generation of Codes, P. Fajfar and H. Krawinkler, Eds., A. A. Balkema, Rotterdam, Netherlands, 1997pp. 69-78, Proceedings of International Conference at Bled, Slovenia.

[18] K. Kawashima, "The 1996 Japanese seismic design specifications of highway bridges and the performance based design," in Seismic Design Methodologies for the Next Generation of Codes, P. Fajfar and H. Krawinkler, Eds., A. A. Balkema,
Rotterdam, Netherlands, 1997pp. 371-382, Proceedings of the International Conference at Bled, Slovenia.

[19] A. J. Kappos, "Partial inelastic analysis procedure for optimum capacity design of RC buildings," in Seismic Design Methodologies for the Next Generation of Codes, P. Fajfar and H. Krawinkler, Eds., A. A. Balkema, Rotterdam, Netherlands, 1997pp. 229-240, Proceedings of the International Conference at Bled, Slovenia.

[20] M. J. N. Priestley, "Displacement-based approaches to rational limit states design of new structures. Keynote address," in Proceedings of the 11th European Conference on Earthquake Engineering, Paris, France, September 1998.

[21] FEMA (Federal Emergency Management Agency), Seismic Performance Assessment of Buildings: Volume 1-Methodology, FEMA P-581, FEMA, Washington, DC, USA, 2012.

[22] M. J. N. Priestley, "Performance based seismic design," in Proceedings of the 12th World Conference on Earthquake Engineering, Auckland, New Zealand, January 2000.

[23] M. Fragiadakis and M. Papadrakakis, "Performance-based optimum seismic design of reinforced concrete structures," Earthquake Engineering \& Structural Dynamics, vol. 37, no. 6, pp. 825-844, 2008.

[24] S. Ganzerli, C. P. Pantelides, and L. D. Reaveley, "Performance-based design using structural optimization," Earthquake Engineering \& Structural Dynamics, vol. 29, no. 11, pp. 1677-1690, 2000.

[25] T. Okada, H. Hiraishi, Y. Ohashi et al., "A new framework for performance-based design of building structures," in Proceedings of the 12th World Conference on Earthquake Engineering, Auckland, New Zeland, January 2000.

[26] R. Park and T. Paulay, Reinforced Concrete Structures, John Wiley \& Sons, New York, NY, USA, 1975.

[27] A. J. Kappos, "Evaluation of behaviour factors on the basis of ductility and overstrength studies," Engineering Structures, vol. 21, no. 9, pp. 823-835, 1999.

[28] E. Miranda and V. V. Bertero, "Evaluation of strength reduction factors for earthquake-resistant design," Earthquake Spectra, vol. 10, no. 2, pp. 357-379, 1994.

[29] A. M. Mwafy and A. S. Elnashai, "Calibration of force reduction factors of RC buildings," Journal of Earthquake Engineering, vol. 6, no. 2, pp. 239-273, 2002.

[30] N. M. Newmark and W. J. Hall, Earthquake Spectra and Design, Earthquake Engineering Research Institute (EERI), El Cerrito, CA, USA, 1982.

[31] A. S. Elnashai and R. Pinho, "Repair and retrofitting of rc walls using selective techniques," Journal of Earthquake Engineering, vol. 2, no. 4, pp. 525-568, 1998.

[32] M. G. Ireland, S. Pampanin, and D. K. Bull, "Experimental investigations of a selective weakening approach for the seismic retrofit of r.c. walls," in Proceedings of the NZSEE Conference 2007, Palmerston North, New Zealand, March 2007.

[33] V. Ligabue, S. Pampanin, and M. Savoia, "Seismic performance of alternative risk-reduction retrofit strategies to support decision making," Bulletin of Earthquake Engineering, vol. 16, no. 7, pp. 3001-3030, 2018.

[34] S. Viti, G. P. Cimellaro, and A. M. Reinhorn, "Retrofit of a hospital through strength reduction and enhanced damping," Smart Structures and Systems, vol. 2, no. 4, pp. 339-355, 2006.

[35] J. Moehle and G. Deierlein, "A framework methodology for performance-based earthquake engineering," in Proceedings of the 13th World Conference on Earthquake Engineering, 
Stanford University, Vancouver, Canada, Paper No. 679, Vancouver, Canada, August 2004.

[36] T. Y. Yang, J. Moehle, B. Stojadinovic, and A. Der Kiureghian, "Seismic performance evaluation of facilities: methodology and implementation," Journal of Structural Engineering, vol. 135, no. 10, pp. 1146-1154, 2009.

[37] D. Vamvatsikos and C. A. Cornell, "Incremental dynamic analysis," Earthquake Engineering \& Structural Dynamics, vol. 31, no. 3, pp. 491-514, 2002.

[38] V. Silva, S. Akkar, J. Baker et al., "Current challenges and future trends in analytical fragility and vulnerability modeling," Earthquake Spectra, vol. 35, no. 4, pp. 1927-1952, 2019.

[39] WBDG (Whole Building Design Guide), 2021, https://www. wbdg.org.

[40] OpenSEES (Open System for Earthquake Engineering Simulation), 2016, http://opensees.berkeley.edu.

[41] L. Berto, M. Bovo, I. Rocca, A. Saetta, and M. Savoia, "Seismic safety of valuable non-structural elements in RC buildings: floor response spectrum approaches," Engineering Structures, vol. 205, Article ID 110081, 2020.

[42] PEER (Pacific Earthquake Engineering Research), 2016, http://ngawest2.berkeley.edu.

[43] M. Zucconi, M. Bovo, F. Romano, and B. Ferracuti, "Application of bidirectional ground motion on existing RC building for seismic loss analysis," AIP Conference Proceedings, vol. 2293, 2020 Proceedings of the ICNAAM 2019, Rhodes, Greece, Article ID 240003.

[44] J. Baker, T. Lin, S. K. Shahi, and N. Jayaram, "New ground motion selection procedures and selected motions for the PEER transportation research program," PEER Report 2011/ 03, University of California, Berkeley, CA, USA, 2011.

[45] FEMA (Federal Emergency Management Agency), Seismic Performance Assessment of Buildings: Volume 3- Performance Assessment Calculation Tool (PACT) Version 2.9.65 FEMA P-583.1), FEMA, Washington, DC, USA, 2012.

[46] USGS (United States Geological Survey), 2020, https://www. usgs.gov.

[47] M. Bovo and N. Buratti, "Evaluation of the variability contribution due to epistemic uncertainty on constitutive models in the definition of fragility curves of RC frames," Engineering Structures, vol. 188, pp. 700-716, 2019. 